\title{
Impact of nanoparticle size and lattice oxygen on water oxidation on NiFeOxHy
}

Roy, C.; Sebok, Béla; Scott, B.; Fiordaliso, E.M.; Sørensen, J.E.; Bodin, A.; Trimarco, D.B.; Damsgaard, C.D.; Vesborg, P.C.K.; Hansen, O.

Total number of authors:

13

Published in:

Nature Catalysis

Link to article, DOI:

$10.1038 / \mathrm{s} 41929-018-0162-\mathrm{x}$

Publication date:

2018

Document Version

Peer reviewed version

Link back to DTU Orbit

Citation (APA):

Roy, C., Sebok, B., Scott, B., Fiordaliso, E. M., Sørensen, J. E., Bodin, A., Trimarco, D. B., Damsgaard, C. D., Vesborg, P. C. K., Hansen, O., Stephens, I. E. L., Kibsgaard, J., \& Chorkendorff, I. (2018). Impact of

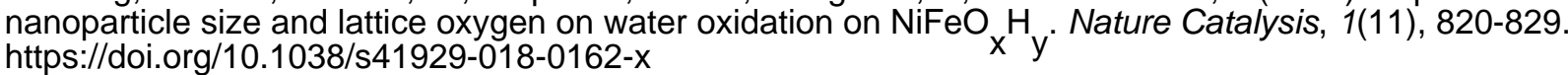

\section{General rights}

Copyright and moral rights for the publications made accessible in the public portal are retained by the authors and/or other copyright owners and it is a condition of accessing publications that users recognise and abide by the legal requirements associated with these rights.

- Users may download and print one copy of any publication from the public portal for the purpose of private study or research.

- You may not further distribute the material or use it for any profit-making activity or commercial gain

- You may freely distribute the URL identifying the publication in the public portal 


\section{Impact of Size and Lattice Oxygen on Water Oxidation on $\mathrm{NiFeO}_{x} \mathrm{H}_{y}$}

C. Roy, ${ }_{1}^{1 \S}$ B. Sebök,${ }^{1 \S}$ S. B. Scott,${ }^{1 \S}$ E. M. Fiordaliso, ${ }^{2}$ J. E. Sørensen, ${ }^{1}$ A. Bodin, ${ }^{1}$ D. B. Trimarco, ${ }^{1}$ C. D. Damsgaard, ${ }^{2}$ P.C.K. Vesborg, ${ }^{1}$ O. Hansen, ${ }^{3}$ I.E.L. Stephens, ${ }^{1,4}$ J. Kibsgaard, ${ }^{1}$ and I. Chorkendorff ${ }^{1}$

1: SurfCat, Department of Physics, Technical University of Denmark, Fysikvej 311, DK2800 Kgs. Lyngby

2: Center for Electron Nanoscopy, Technical University of Denmark, Fysikvej 307 and 314, DK-2800 Kgs. Lyngby

3: Department of Micro- and Nanotechnology, Technical University of Denmark, Ørsteds Plads B.344, DK-2800 Kgs. Lyngby

4: Department of Materials, Imperial College London, Royal School of Mines Exhibition Road, London, SW7 2AZ - UK

$\S$ These authors contributed equally to this work

Correspondence to: Prof. Ib Chorkendorff (ibchork@fysik.dtu.dk) 


\begin{abstract}
$\mathrm{Ni}(\mathrm{Fe}) \mathrm{O}_{\mathrm{x}} \mathrm{H}_{\mathrm{y}}$ are the most active catalysts for oxygen evolution in base. For this reason, they are used widely in alkaline electrolysers. Several open questions remain regarding the reason for their exceptionally high catalytic activity. Here we use a model system of mass-selected NiFe nanoparticles and isotope labelling experiments to show that oxygen evolution in $1 \mathrm{M} \mathrm{KOH}$ does not proceed via lattice exchange. We complement our activity measurements with electrochemistry-mass spectrometry, taken under operando conditions, and transmission electron microcopy and low energy ion scattering spectroscopy, taken ex situ. Together with particle size trends, the isotope results indicate that oxygen evolution is limited to the near surface region. Using the surface area of the particles, we determine that the turnover frequency is $6.2 \pm 1.6 \mathrm{~s}^{-1}$ at an overpotential of $0.3 \mathrm{~V}$, which is, to the best of our knowledge, the highest reported for oxygen evolution in alkaline solution.
\end{abstract}




\section{Introduction}

Renewable energy technologies, such as wind turbines and solar panels, hold the potential to satisfy rising global energy demand while mitigating $\mathrm{CO}_{2}$ emissions ${ }^{1,2}$. Because of the intermittent nature of wind and solar energy, energy storage is one of the most critical challenges limiting their widespread implementation. One possibility is to store the energy in chemical bonds ${ }^{3}$. Thus far, one of the most promising means of converting electricity to fuels is water electrolysis where $\mathrm{H}_{2}$ and $\mathrm{O}_{2}$ gasses are formed ${ }^{4}$. Their recombination to provide electrical energy has only water as by-product, making it a clean process.

The hydrogen evolution reaction (HER), which takes place on the cathode side during water electrolysis, is possible at minimal energy losses ${ }^{5,6}$. However, the slow reaction kinetics of the anodic reaction, the oxygen evolution reaction (OER) involving the transfer of 4 electrons and 4 protons, limits the efficiency of electrolyzers ${ }^{7}$. No electrode material approaches the equilibrium potential of $1.23 \mathrm{~V}$ on the reversible hydrogen electrode scale $\left(\mathrm{V}_{\mathrm{RHE}}\right)^{8-10}$, corresponding to the minimum energy needed for the reaction. Consequently, the widespread use of electrolysers is contingent on improvements to the OER kinetics.

While $\mathrm{Ni}(\mathrm{Fe}) \mathrm{O}_{x} \mathrm{H}_{\mathrm{y}}$ mixed electrodes were already used in the $19^{\text {th }}$ century in alkaline electrolysers ${ }^{11}$, the origin of the activity is still under intense debate ${ }^{12,13}$. Pure $\mathrm{NiO}_{x} \mathrm{H}_{\mathrm{y}}$ is an inactive catalyst, but the activity drastically increases when $\mathrm{Fe}$ intercalates into the structure ${ }^{12-16}$, with optimal activity for compositions between $10 \%$ and $50 \% \mathrm{Fe}^{13}$. There are two main hypotheses regarding the role of $\mathrm{Fe}$ : (i) $\mathrm{Ni}$ is the active site and $\mathrm{Fe}$ affects its valency, making it more active ${ }^{17,18}$; or (ii) Fe itself is the active site ${ }^{19-22}$, as first evidenced by Friebel et al using x-ray adsorption spectroscopy and DFT calculations ${ }^{19}$, and subsequently by Ahn and Bard using electrochemical scanning microscopy ${ }^{22}$. Conversely, more recently, Goddard and co-workers suggested that both $\mathrm{Ni}$ and $\mathrm{Fe}$ sites are directly involved $^{23}$.

Some studies have indicated that the bulk, and not just the outer surface, of the catalyst is active. For example, Boettcher and co-workers reported a linear increase of the OER current as a function of catalyst loading up to $\sim 450$ monolayer equivalents ${ }^{24}$. The notion of bulk activity was supported by a recent theoretical study by Vojvodic and co-workers ${ }^{25}$, where they found similar thermodynamics for the OER intermediates in the bulk of the material as the (001) surface. On the other hand, $\mathrm{Hu}$ and co-workers showed that the apparent turnover frequency of $\mathrm{NiFeO}_{x}$ decreases at high loading ${ }^{26}$, either suggesting that thick samples are not as active or that the OER becomes readily transport limited.

Earlier studies have probed $\mathrm{Ni}^{3+, 4+} / \mathrm{Ni}^{2+}$, redox chemistry on $\mathrm{NiFeO}_{x} \mathrm{H}_{y}$ electrodes at $\sim 1$.31.4 $\mathrm{V}_{\mathrm{RHE}}$, using cyclic voltammetry and gravimetric analysis; they concluded that each nickel atom in the film contributes on average approximately one electron ${ }^{24,27}$. This 
observation indicates that the entire film is electrochemically accessible, motivating the hypothesis that oxygen evolution occurs between the nanosheets of the layered double hydroxide structure of the catalyst, blurring the distinction between surface and bulk ${ }^{14}$. Moreover, $\mathrm{NiFeO}_{x} \mathrm{H}_{y}$ films, which are typically electrodeposited, are highly porous ${ }^{13}$. These various studies point to three possibilities: (i) activity confined to an outer surface, which may be large for porous materials, (ii) activity confined to a near surface region in which there is ionic conductivity and electrolyte intercalated between the nanosheets, and (iii) bulk activity in which the entire material is active. This complicates the determination of the intrinsic activity, a critical step towards designing more efficient OER catalysts, and motivates the use of a model system with a known and well-defined surface area ${ }^{14}$.

Isotope labelling studies using ${ }^{18} \mathrm{O}$ and operando mass spectrometry are a powerful tool to distinguish surface from bulk catalysis ${ }^{28}$. Most of the catalysts probed using this method have revealed at least some degree of lattice oxygen involvement, including $\mathrm{Au}^{29}, \mathrm{IrO}_{2} / \mathrm{T}^{30}$, $\mathrm{Co}_{3} \mathrm{O}_{4}$ spinel ${ }^{31}$, molecular cobaltate nano-clusters ${ }^{32}$, Ru-based catalysts ${ }^{28,33}$ and perovskite materials with high metal-oxygen bond covalency ${ }^{34}$. Others, including $\mathrm{Pt}^{35}$, oriented thin films of rutile $\mathrm{RuO}_{2}{ }^{36}$ and perovskites with low metal-oxygen bond covalency ${ }^{34}$, have not. Shao-Horn and co-workers observed that lattice exchange occurs with materials that have a catalytic activity that is $\mathrm{pH}$ dependent, indicating decoupled proton and electron transfers in the OER mechanism ${ }^{34}$. Based on that argument, $\mathrm{Ni}(\mathrm{Fe}) \mathrm{O}_{x} \mathrm{H}_{\mathrm{y}}$, which shows higher catalytic activity in stronger alkaline electrolyte, should also show participation of lattice oxygen ${ }^{37}$. However, to the best of our knowledge, no studies have probed $\mathrm{Ni}(\mathrm{Fe}) \mathrm{O}_{x} \mathrm{H}_{\mathrm{y}}$ using isotopically labelled water, even though it is the catalyst-of-choice for industrial water electrolysis.

Such isotope studies consist of preparing $\mathrm{NiFeO}_{x} \mathrm{H}_{y}$ catalyst with one oxygen isotope $\left({ }^{16} \mathrm{O}\right.$ or ${ }^{18} \mathrm{O}$ ) or isotopic ratio, and then monitoring the $\mathrm{O}_{2}$ products during oxygen evolution in an electrolyte having a different isotopic ratio using a mass spectrometer $\left({ }^{16} \mathrm{O}_{2}\right.$ at $\mathrm{m} / \mathrm{z}=32$, ${ }^{16} \mathrm{O}^{18} \mathrm{O}$ at $\mathrm{m} / \mathrm{z}=34$, and $/ \mathrm{or}{ }^{18} \mathrm{O}_{2}$ at $\mathrm{m} / \mathrm{z}=36$ ). Should the $\mathrm{O}_{2}$ evolved differ from the isotopic composition of the electrolyte, then it is likely derived from the lattice oxygen or from water molecules intercalated between the layered nanosheets.

Drawing a conclusion on participation of lattice oxygen requires high sensitivity and thorough characterization: (i) to ensure that the isotopic oxygen is included in the $\mathrm{NiFeO}_{x} \mathrm{H}_{\mathrm{y}}$ catalyst, (ii) to correctly identify whether it is evolved during the OER, and iii) to quantify accurately that amount. To satisfy these requirements, we used a microchipbased electrochemistry-mass spectrometry technology that has high sensitivity. For example, it can detect 0.05 monolayer equivalents of $\mathrm{H}_{2}$ desorbing from a flat Pt surface with a signal-to-noise ratio of $\sim 20^{38}$. We complement the operando mass spectrometry experiments with post-characterization by low-energy ion scattering (LEIS), a surface sensitive technique enabling the differentiation of ${ }^{16} \mathrm{O}$ and ${ }^{18} \mathrm{O}$. 
In the present study, we prepared size-selected NiFe particles using a magnetron sputtering nanoparticle source (Figure 1a). This physical synthesis method yields homogenous, monodisperse and chemically pure metallic particles, with a well-defined size and loading, ideal for fundamental studies ${ }^{39,40}$. We compare the nanoparticles to $\mathrm{NiFeO}_{x} \mathrm{H}_{\mathrm{y}}$ electrodeposited thin films. We test the catalytic activity using a rotating disk electrode assembly in $1.0 \mathrm{M} \mathrm{KOH}$, where the particles oxidize under operando conditions. We complement these experiments with X-ray photoelectron spectroscopy (XPS), highresolution transmission electron microscopy (HRTEM) and scanning electron microscopy (SEM), and perform isotope studies as described above. The nanoparticle samples function as a model system with a well-defined and tunable surface area.

Together, the nanoparticle model system, extensive characterization, and isotope studies enable us to answer two fundamental questions: (i) What is the intrinsic activity of the active sites on a well-defined surface of $\mathrm{NiFeO}_{x} \mathrm{H}_{y}$, and (ii) does lattice oxygen participate in the reaction?

\section{Results}

\section{NiFe model system}

Figure $1 \mathrm{~b}$ shows the size distribution of the as-prepared nanoparticles. The size distribution was determined by TEM as described in Supplementary Note 1. As presented in Figure $1 \mathrm{~b}$, all nanoparticles have a regular and spherical shape regardless of their mass. The average particle diameters are $3.9 \pm 0.5 \mathrm{~nm}, 5.4 \pm 0.5 \mathrm{~nm}, 6.7 \pm 0.6 \mathrm{~nm}$, and $8.4 \pm 0.5 \mathrm{~nm}$, respectively, for the four selected masses, as shown in Figure 1c. There is a small population of larger particles with double the intended mass, resulting from doubly charged nanoparticles, especially in case of the $8.4 \mathrm{~nm}$ particles.

\section{Stability and effects of OER operating conditions}

The $6.7 \mathrm{~nm}$ nanoparticles were characterized with LEIS and XPS, as shown in Figure 2a and $b$, respectively. The LEIS spectra of the as-deposited nanoparticles (green curve) show clear $\mathrm{Ni}$ and $\mathrm{Fe}$ peaks, which cannot be differentiated due to the small difference between their atomic masses. After electrochemical testing (blue curve), the LEIS spectra show additional features identified as $\mathrm{K}, \mathrm{O}$ and $\mathrm{C}$, most probably from residual $\mathrm{KOH}$ electrolyte, nanoparticle oxidation, and air exposure. XPS spectra (Figure 2b) of the asdeposited nanoparticles reveal metallic $\mathrm{Ni}$ and $\mathrm{Fe}$. XPS analysis after electrochemical treatment shows that oxide and hydroxide states are formed for both $\mathrm{Ni}$ and $\mathrm{Fe}$. More precisely, $\mathrm{NiO}$ and $\mathrm{Ni}(\mathrm{OH})_{2}$, and $\mathrm{FeOOH}$ and $\mathrm{Fe}_{2} \mathrm{O}_{3}$, are identified from the $\mathrm{Ni}$ and $\mathrm{Fe} 2 \mathrm{p}$ peaks, respectively. The composition determined based on the XPS spectra shows similar 
Fe content before electrochemical testing to the target for the deposition, namely $25 \%$, and an $\mathrm{Fe}$ content of $\sim 15 \%$ after electrochemical testing for all nanoparticle sizes (Supplementary Note 3).

One challenge with nanoparticle catalysts is that they often coalesce under reaction conditions $^{41-43}$. In addition, the conditions under which OER electrodes operate can cause metal dissolution ${ }^{44,45}$. As a first step to evaluate the stability and resistance towards corrosion and sintering, SEM images were acquired before and after OER at identical locations to directly visualize any change in particle size or positions ${ }^{46}$. From the example images shown in Figure $2 c$ taken before and after testing the activity, it can be seen that the $5.4 \mathrm{~nm} \mathrm{NiFe}$ particles do not coalesce or dissolve during the $2 \mathrm{~h}$ potentiostatic measurement at 1.6 $\mathrm{V}_{\mathrm{RHE}}$. Most of the nanoparticles can be directly found in both images. To further probe the stability, a chronoamperometric measurement was performed at 1.6 $\mathrm{V}_{\mathrm{RHE}}$. As presented in Figure 3, the OER current was stable over 41 days $(\sim 1000 \mathrm{~h})$. This result further confirms the stability of NiFe catalyst previously reported by stable chronoamperometric measurement at $10 \mathrm{~mA} / \mathrm{cm}^{2}$ over $24 \mathrm{~h}^{47,48}$.

To gain insight into the morphology and composition at the atomic level, we acquired identical location HRTEM images of particles deposited on graphene covered Au TEM grids both before and after two cyclic voltammetry cycles (CVs) at $10 \mathrm{mV} / \mathrm{s}$ up to $1.5 \mathrm{~V}_{\mathrm{RHE}}$. The electrochemical treatment was mild to avoid the corrosion of the carbon grid at more anodic potentials. Before OER, the NiFe nanoparticles show polycrystalline structure. An example image in Figure $4 \mathrm{a}$ shows a single particle in which the $\mathrm{Ni}_{3} \mathrm{Fe}$ phase can be identified $^{49}$. Figure $4 \mathrm{~b}$ and $4 \mathrm{c}$ show HRTEM images of the same nanoparticles before and after being electrochemically tested. We found that after electrochemical testing, the nanoparticles maintain their shape and their polycrystalline nature, as indicated by the non-uniform orientation of lattice fringes, and by the contrast difference caused by diffraction. We used EDX along with focused electron beam to map the dispersion of $\mathrm{Ni}$ and $\mathrm{Fe}$ in the particles using cross sectional line scans (Supplementary Note 4). The comparison of the $\mathrm{Ni}$ and $\mathrm{Fe}$ concentration before and after electrochemical testing shows that some of the Fe leaches out after OER. This decrease in Fe concentration could be associated to the dissolution of $\mathrm{FeOOH}$, known to be highly unstable under these experimental conditions ${ }^{50}$.

\section{Activity}

Representative CVs of samples from each of the four nanoparticle size groups, taken after 2 hours at $1.6 \mathrm{~V}_{\mathrm{RHE}}$, are plotted in Figure $5 \mathrm{a}$ showing a clear difference in activity for the different particle sizes. The smallest particles, i.e. $3.9 \mathrm{~nm}$ and $5.4 \mathrm{~nm}$, provide the highest current normalized to the deposited metal mass. A significant OER current is observed starting from $U=\sim 1.5 \mathrm{~V}_{\mathrm{RHE}}$ (overpotential of $\eta=270 \mathrm{mV}$ ). Using what is typically attributed to $\mathrm{Ni}^{2+}$ to $\mathrm{Ni}^{3+/ 4+}$ redox couple ${ }^{13}$, we showed that the integral of the Ni reduction peak scales better with the calculated surface area than the total loading (Supplementary 
Figure 4). Less than one electron is transferred per $\mathrm{Ni}$ atom in the larger nanoparticles. Figure $5 \mathrm{~b}$ shows the average mass activity on deposited metal basis at $\eta=270,300$ and $370 \mathrm{mV}$ as a function of particle size. The activity was taken from the current recorded at a scan rate of $10 \mathrm{mV} / \mathrm{s}$. No obvious difference in trend is observed when comparing the mass activity as a function of size for different overpotentials.

To determine the intrinsic activity, we convert the activity to turnover frequency (TOF), i.e. the number of $\mathrm{O}_{2}$ molecules produced per active site per unit time, using three estimates for the number of active sites. TOF bulk assumes that all deposited $\mathrm{Ni}$ and $\mathrm{Fe}$ atoms are active, TOF $_{\text {redox }}$ assumes one active site per electron transferred in the Ni reduction peak of the $\mathrm{CV}$, and $\mathrm{TOF}_{\text {surface }}$ assumes that only the surface metal atoms of the nanoparticles are active sites (see Methods Section Equation 1-6). We also include the TOF redox calculated for $\mathrm{NiFeO}_{x} \mathrm{H}_{y}$ thin films, for which the activity was measured by the same procedure as the nanoparticles (Supplementary Figure 5).

The TOFs thus calculated show different trends with particle size. TOF bulk $_{\text {is }}$ higher for the smaller particles, i.e. $5.4 \mathrm{~nm}$ and $3.9 \mathrm{~nm}$, and lower for the larger particles. TOF redox and TOF $_{\text {surace }}$ do not show any obvious particle size dependence, though TOF redox has a larger scatter.

The TOF surface $_{\text {and }}$ TOF bulk $_{\text {of }}$ the $5.4 \mathrm{~nm}$ NiFe nanoparticles were compared to state-of-theart non-noble metal catalysts for the OER in alkaline media (Figure $6 \mathrm{~b}$ ). The reaction rate of $5.4 \mathrm{~nm}$ NiFe particles at $1.53 \mathrm{~V}_{\mathrm{RHE}}(\eta=300 \mathrm{mV})$ of $6.2 \pm 1.6 \mathrm{~s}^{-1}$ (TOF surface) and $1.2 \pm$ $0.3 \mathrm{~s}^{-1}\left(\mathrm{TOF}_{\text {buk }}\right)$ are among the highest reported for non-noble metal catalysts in alkaline electrolyte ${ }^{4,16,27,47,51-54}$.

\section{Isotope labelling experiments}

To provide further insight on which TOF represents the true intrinsic activity, we used three complimentary isotope labelling procedures, all on samples with $6.7 \mathrm{~nm}$ particles, referred to below as procedure $a, b$, and $c$, and illustrated schematically in Figure 7 . Because of the natural oxidation of $\mathrm{NiFe}$ particles when exposed to air, we oxidized the catalyst in $\mathrm{H}_{2}{ }^{16} \mathrm{O}$ and performed OER in ${ }^{18} \mathrm{O}$-based electrolyte (procedure a). We also oxidized the $\mathrm{NiFe}$ particles in $\mathrm{H}_{2}{ }^{18} \mathrm{O}$ (procedure $b$ ) and ${ }^{18} \mathrm{O}_{2}$ atmosphere (procedure $c$ ) to study the possible differences between hydroxide and oxide compounds.

In procedure $a,{ }^{16} \mathrm{O}$ is incorporated into the NiFe nanoparticles through cycling in $0.1 \mathrm{M}$ $\mathrm{KOH}$ made from ultrapure water, and the oxygen evolution process takes place in $0.1 \mathrm{M}$ $\mathrm{KOH}$ made from ${ }^{18} \mathrm{O}$ water $\left(\sim 97 \%{ }^{18} \mathrm{O}\right)$. Due to the natural abundance of ${ }^{16} \mathrm{O}$, this has the advantage that the nanoparticles can easily be prepared with $99.8 \%{ }^{16} \mathrm{O}$. On the other hand, the lower purity of ${ }^{18} \mathrm{O}$-labeled water limits the sensitivity towards isotope exchange of the subsequent EC-MS measurement. In procedures $b$ and $c,{ }^{18} \mathrm{O}$ is incorporated in the NiFe structure either by cycling in ${ }^{18} \mathrm{O}$-labelled $0.1 \mathrm{M} \mathrm{KOH}$ electrolyte, or by heating at 450 ${ }^{\circ} \mathrm{C}$ in the vacuum chamber in the presence of ${ }^{18} \mathrm{O}_{2}$ gas, respectively. This allows for greater 
sensitivity towards lattice exchange, but adds some uncertainty to the initial isotopic composition of the catalyst.

In procedure $a$, the sample of deposited particles were cycled in $0.1 \mathrm{M} \mathrm{KOH}$ made from ultrapure water until a stable $\mathrm{CV}$ was obtained, i.e. 20 cycles $0.5-1.5 \mathrm{~V}_{\mathrm{RHE}}$. At this point we assumed that the catalyst is in the fully oxygenated form, nominally $M\left({ }^{16} \mathrm{OH}\right)_{2}$ where $\mathrm{M}=\mathrm{Ni}_{\mathrm{x}} \mathrm{Fe}_{1-\mathrm{x}}$. The electrode is then transferred at open-circuit voltage to a stagnant thin-layer cell filled with ${ }^{18} \mathrm{O}$-labeled $0.1 \mathrm{M} \mathrm{KOH}$ for measurement by EC-MS. The first cycle up to $1.55 \mathrm{~V}_{\mathrm{RHE}}$ and back to $0.5 \mathrm{~V}_{\mathrm{RHE}}$ is shown in Figure 8a-b. In Figure $8 \mathrm{a}$, the calibrated $\mathrm{m} / \mathrm{z}=34$ $\left({ }^{16} \mathrm{O}^{18} \mathrm{O}\right)$ mass spectrometer signal is plotted (red trace) as a function of time, and in Figure $8 \mathrm{~b}$ the potential and current are plotted on the same time axis. Co-plotted with the measured ${ }^{16} \mathrm{O}^{18} \mathrm{O}$ signal in Figure $8 \mathrm{a}$ is the expected ${ }^{16} \mathrm{O}^{18} \mathrm{O}$ signal (green dotted trace) due to oxidation of the electrolyte, which contains only $\sim 97 \%{ }^{18} \mathrm{O}$. The expected ${ }^{16} \mathrm{O}^{18} \mathrm{O}$ signal is the measured ${ }^{18} \mathrm{O}_{2}(\mathrm{~m} / \mathrm{z}=36)$ signal multiplied by the steady-state ${ }^{16} \mathrm{O}^{18} \mathrm{O} /{ }^{18} \mathrm{O}_{2}$ ratio. This ratio, as well as the calibration, were determined under operando conditions by steadystate oxygen evolution (Supplementary Note 5). The measured and expected ${ }^{16} \mathrm{O}^{18} \mathrm{O}$ coincide, indicating that all of the signal at $\mathrm{m} / \mathrm{z}=34$ can be explained by oxidation of the electrolyte alone. The onset of the oxygen signal is delayed with respect to the onset of OER current by about $\sim 3 \mathrm{~s}$ as predicted by the mass-transport model described in reference ${ }^{38}$, indicating that the current at low overpotential does indeed go to OER and not another process.

To illustrate the sensitivity, we have included in Figure $8 a$ the expected excess $\mathrm{m} / \mathrm{z}=34$ signal if $1 \%$ of the total ${ }^{16} \mathrm{O}$ contained by the catalyst, equivalent to approximately $10 \%$ of a monolayer, were released as ${ }^{16} \mathrm{O}^{18} \mathrm{O}$. The release of $1 \%$ of the total ${ }^{16} \mathrm{O}$ in 45 seconds (dotted blue trace), which would correspond to approximately $0.2 \%$ of a ML per second, is significantly above the detection limit. In comparison, the peak oxygen signal (at $\mathrm{m} / \mathrm{z}=36$ ) in this scan corresponds to $19 \%$ of a ML per second, or about 100 times greater. This proves that if even one percent of the OER activity were due to lattice oxygen evolution, it would be detectable.

The results of procedures $b$ and $c$ (Supplementary Figure 7a-d) are similar but because of low natural abundance of ${ }^{18} \mathrm{O}(0.02 \%)$ the sensitivity towards isotope exchange at $\mathrm{m} / \mathrm{z}=34$ and 36 is even higher. To determine whether the result is general, we also performed the isotope experiment (following procedure a) on a $\mathrm{NiFeO}_{x} \mathrm{H}_{\mathrm{y}}$ thin film, and again observed no lattice exchange (Supplementary Figure 7e). Additionally, to prove that our setup is indeed sensitive enough to detect lattice exchange when it does take place, we performed the same experiment on $\mathrm{IrO}_{2} / \mathrm{Ti}$ in acid, as described in Reference ${ }^{30}$, and reproduce their result of $>1 \mathrm{ML}$ isotope exchange. This result is directly compared with the one from $\mathrm{NiFeO}_{x} \mathrm{H}_{\mathrm{y}}$ in Supplementary Figure 8.

In procedure a, following EC-MS, the sample was rinsed in $\mathrm{H}_{2}{ }^{18} \mathrm{O}$ before being transferred back to vacuum for LEIS. The LEIS spectrum after OER, i.e. the purple line in Figure $8 \mathrm{c}$, 
shows extra peaks when compared to the initial LEIS spectrum (black line) that we attribute to ${ }^{16} \mathrm{O},{ }^{18} \mathrm{O}$, impurity $\mathrm{Na}$ and $\mathrm{Mg}$ salt deposits from the $\mathrm{H}_{2}{ }^{18} \mathrm{O}$ rinsing, and residual $\mathrm{K}$ from the electrolyte. The sample was then Ar-sputtered for 30 minutes before another LEIS spectrum was taken. This spectrum (blue line) shows an increased ${ }^{16} \mathrm{O} /{ }^{18} \mathrm{O}$ ratio, compared to the initial one. We therefore attribute the ${ }^{18} \mathrm{O}$ peak to residual $\mathrm{K}^{18} \mathrm{OH}$ and/or other hydroxide salts on the surface of the sample and the ${ }^{16} \mathrm{O}$ peak to ${ }^{16} \mathrm{O}$ remaining in the catalyst. After both procedures $b$ and $c$, the ${ }^{18} \mathrm{O} /{ }^{16} \mathrm{O}$ ratio in LEIS after OER, rinsing with ultrapure water, and sputtering, is approximately $1: 1$, with little to no $\mathrm{K}$ or other impurities, as shown in Supplementary Figure 7 . In both cases there is a clear ${ }^{18} \mathrm{O}$ signal even before sputtering, indicating that this isotope is present at the surface of the catalyst. The postsputtering $1: 1$ ratio presumably reflects the nominal $\mathrm{M}\left({ }^{18} \mathrm{OH}\right)\left({ }^{16} \mathrm{OH}\right)$ formula resulting from the experimental procedures as illustrated in Figure $7 \mathrm{~b}$ and $\mathrm{c}$. Because the natural abundance of ${ }^{18} \mathrm{O}$ is so low $(0.2 \%)$, the presence of ${ }^{18} \mathrm{O}$ on the LEIS spectra in procedures $b$ and $c$ implies that it was incorporated during the catalyst preparation before OER, and not during transfer through air from EC-MS to LEIS.

\section{Discussion}

The results obtained from the identical location SEM (Figure 2c), in addition to the stable current over 1,000 hours (Figure 3 ), prove that the $\mathrm{NiFeO}_{x} \mathrm{H}_{y}$ particles are remarkably stable against corrosion.

The activity dependence on particle size is similar at 270,300 and $370 \mathrm{mV}$ overpotential (Figure 5). This is consistent with a lack of subsurface activity, which would involve the diffusion of water and oxygen through the nanoparticles, and could therefore introduce greater mass transport limitations for larger particles at high overpotentials, if the diffusion were sufficiently slow. Furthermore, the activity of the particles normalized to surface area, i.e. the turnover frequency per surface metal atom (TOF surface), does not change with particle size (Figure 6a). In contrast, the activity of the particles normalized to total mass, which is proportional to the turnover frequency per metal atom (TOF bulk), decreases with increasing particle size. Differing $\mathrm{Fe}$ content cannot explain the observed trends (Supplementary Figure 2b). $\mathrm{TOF}_{\text {redox }}$ of the electrodeposited $\mathrm{NiFeO}_{\mathrm{x}} \mathrm{H}_{\mathrm{y}}$ film shows similar activity as the one reported by Trotochaud et al. ${ }^{27}$ This is slightly lower than TOF redox for the nanoparticles, also consistent a lack of subsurface activity and the observation that the $\mathrm{Ni}$ redox peak probes more than the Ni surface atoms.

Mass spectrometry and LEIS measurements for isotope experiments on $\mathrm{NiFeO}_{x} \mathrm{H}_{y}$ particles using three different approaches all indicate that oxygen is retained in the catalyst during OER, both in the bulk and, to at least some degree, on the surface of the catalyst as well. Isotope experiments on a $\mathrm{NiFeO}_{x} \mathrm{H}_{y}$ thin film agree. The significance of this result is two-fold: First, it provides additional evidence against activity below the outer surface or a near surface region in which water is highly mobile, as this would involve lattice oxidation 
and/or oxidation of low-mobility intercalated water. Second, the oxygen evolution mechanism does not proceed via lattice oxygen.

Based on the arguments above, we conclude that active sites are limited to a near surface region, and that $\mathrm{TOF}_{\text {redox }}$ is a lower-bound to the intrinsic activity of the active sites. Previous studies showing linear correlation between loading and activity have used porous electrodes without a well-defined outer surface ${ }^{24}$. Given the evidence presented here against bulk activity, we explain this observation on the basis that the surface area scales linearly with loading for these porous materials.

However, determining if activity is limited to the outer surface atomic layer (TOF surface) is more difficult. While the charge passed in the Ni redox feature during cyclic voltammatry corresponds to $\sim 3$ atomic layers, this does not necessarily mean that this entire region also participates in OER. The nature of the transport involved in the Ni redox feature in alkaline is an unsolved problem ${ }^{13}$, and models based on the transport of protons, hydroxide, or cations have all been proposed ${ }^{55}$. Whereas the Ni redox feature may only require shuttling of a proton, OER necessarily requires the net transport of oxygen species. Our isotope result indicates that transport below the outer surface is either so slow as to inhibit OER or fast enough that any water or hydroxide in this region exchanges with the electrolyte before the onset of OER. We must admit that we cannot yet conclusively distinguish between the two possibilities.

As mentioned previously, lattice exchange is material dependent. The phenomenon is observed with $\mathrm{Co}_{3} \mathrm{O}_{4}{ }^{31}$, iridium-based catalysts ${ }^{30}$ and a few perovskites ${ }^{34}$. Besides being sensitive to the composition of the material, the lattice oxygen exchange seems to be also dependent on the structure. Indeed, lattice exchange was observed with amorphous and nanocrystaline $\mathrm{RuO}_{2}$ phases with undercoordinated edge-sites ${ }^{28,33}$ but not with crystalline rutile $\mathrm{RuO}_{2}{ }^{36}$. While we did not observe lattice exchange during OER in the case of $\mathrm{NiFeO}_{x} \mathrm{H}_{y}$ nanoparticles or an electrodeposited $\mathrm{NiFeO}_{x} \mathrm{H}_{y}$ thin film, the results may not be generalizable to all synthesis methods. Furthermore, we cannot rule out that such phenomena could in principle occur at much higher potentials which, unfortunately, cannot yet be studied in our EC-MS setup, due to bubble formation.

The absence of participation of lattice oxygen in $\mathrm{NiFeO}_{x} \mathrm{H}_{y}$ is in disagreement with the hypothesis that lattice exchange should occur with materials that have a catalytic activity that is $\mathrm{pH}$-dependent on the hydrogen scale ${ }^{34}$, as this is the case for $\mathrm{NiFeO}_{\mathrm{x}} \mathrm{H}_{\mathrm{y}}{ }^{56}$. In contrast, it provides evidence for an associative mechanism, such as that proposed by Bell and co-workers ${ }^{19}$.

\section{Conclusion}

In summary, we used well-characterized mass-selected nanoparticles of $\mathrm{Ni}$ and $\mathrm{Fe}$ as a model system to investigate their fundamental properties under oxygen evolution conditions. We provided fundamental insight into the reaction and the origin of its high 
performance using low-energy ion scattering and the microchip-based electrochemistrymass spectrometry setup. The particles show exceptionally high activity and stability over $1000 \mathrm{~h}$ at $1.6 \mathrm{~V}_{\text {RHE. }}$. Isotope-labelling experiments performed following three distinct approaches show that there is no participation of lattice oxygen or intercalated water in the oxygen evolution. This allows us to conclude that the active sites responsible for such exceptional activity are only located in the $\sim 3$ atomic layer redox-active near surface region of the nanoparticles, but determining if activity is limited to the outer surface would require better knowledge of the ionic transport mechanisms within this region. Normalizing the activity to the outer surface results in a TOF of $6.2 \pm 1.6 \mathrm{~s}^{-1}$ at $\eta=0.3 \mathrm{~V}$, the highest reported to date. Further enhancements to the catalytic activity should focus on tailoring the atoms at the near surface region, as opposed to the bulk. 


\section{Methods:}

\section{Preparation of mass-selected NiFe nanoparticles}

NiFe nanoparticles were prepared using a noble gas-aggregation, magnetron sputtering nanoparticle source combined with a lateral time-of-flight mass filter (Figure 1a) capable of mass selection of the nanoparticles before deposition ${ }^{57}$ (Nano-Beam 2011, Birmingham Instruments Ltd.) similar to the one described by Pratontep et al ${ }^{58}$. A 75 at $\% \mathrm{Ni} / 25$ at $\% \mathrm{Fe}$ sputtering target $(99.95 \%$, Kurt J. Lesker Ltd., UK) was used and the particles were deposited onto clean and smooth Au disks. The nanoparticle source is fully UHV compatible and the mass filter has a base pressure in the low $10^{-10} \mathrm{mbar}$ region. The mass filter was set to be used with negatively charged particles, and to have a mass resolution of approx. $\mathrm{m} / \Delta \mathrm{m}=20$ to maximize the current of particles. The vast majority of the particles exiting the nanoparticle source is carrying a single charge, thus the current measured on the sample during the deposition together with the deposition time can be translated into the number of deposited particles. If not otherwise stated, the loading of the electrodes was $15 \%$ projected surface area coverage, which corresponds to a total metal mass loading of $50-125 \mathrm{ng}$ meaning $315-785 \mathrm{ng} / \mathrm{cm}^{2}$ loading in circular spots having 4.5 $\mathrm{mm}$ diameter depending on particle size.

\section{Determination of particle size distributions}

NiFe nanoparticles with masses of 120,000, 350,000, 950,000 and 2,000,000 amu were deposited onto Cu TEM grids covered with lacey carbon (300 mesh, Agar Scientific Ltd., UK). After deposition and transfer under atmospheric conditions, the particles were imaged in bright-field TEM mode in an FEI Tecnai T20 $\mathrm{G}^{2}$ equipped with a thermionic electron source, using $200 \mathrm{keV}$ acceleration voltage. The images were analyzed with ImageJ software to extract the average area of the particle projections, and a diameter was calculated assuming circular shape (Supplementary Note 1).

\section{Electrochemical measurements}

Electrochemical measurements were performed using a rotating disk electrode in a PTFE (Teflon) cell at $1,600 \mathrm{rpm}$ in $\mathrm{N}_{2}$-saturated $1.0 \mathrm{M} \mathrm{KOH}$. A carbon rod was used as counter electrode, while a $\mathrm{Hg} / \mathrm{HgO}$ electrode was used as reference electrode, which was calibrated to the reversible hydrogen electrode (RHE) in the same electrolyte saturated with 1 bar $\mathrm{H}_{2}$ over a clean $\mathrm{Pt}$ mesh before each experiment. The Ohmic drop was measured by using electrochemical impedance spectroscopy over a range of 10-200,000 $\mathrm{Hz}$ at an AC amplitude of $10 \mathrm{mV}$. The high-frequency intercept was fitted to an equivalent circuit to obtain the Ohmic losses which typically ranged from 4 to $18 \quad \Omega$. The Ohmic drop compensation was done by online Ohmic drop correction where $85 \%$ correction was applied. 1.0 M KOH was prepared from ultrapure water (Milli-Q, $18 \mathrm{M} \Omega \mathrm{cm}$ ) with $\mathrm{KOH}$ 
(Semiconductor grade, pellets, 99.9\%). The initial catalytic activity was measured by recording 5 cyclic voltammograms (CVs) at $10 \mathrm{mVs}^{-1}$ up to $1.6 \mathrm{~V}_{\mathrm{RHE}}$ followed by a 2 hour potentiostatic measurement at $1.6 \mathrm{~V}_{\mathrm{RHE}}$. Finally, the activity was again assessed using CVs. The activity of the different samples for the oxygen evolution reaction presented in this work was taken from the last CV. For each experiment, 3 independent samples were tested and the activity was averaged (see Supplementary Figures 9, 10 and 11). The longer stability measurement was a static measurement at $1.6 \mathrm{~V}_{\mathrm{RHE}}$, for which the $\mathrm{NiFe}$ particles were deposited onto a gold sheet. Because of the duration of this experiment, only 2 samples were tested. The mass activity was obtained by normalising the current with the total mass of $\mathrm{Ni}$ and $\mathrm{Fe}$ determined from the deposition current and time.

To compare the differences between lattice oxygen participation in $\mathrm{NiFeO}_{x} \mathrm{H}_{\mathrm{y}}$ nanoparticles and thin film, thin films of $\mathrm{NiFeO}_{x} \mathrm{H}_{\mathrm{y}}$ were electrodeposited. Using a three-electrode setup, a current of $-0.2 \mathrm{~mA} / \mathrm{cm}^{2}$ for $5 \mathrm{~min}$ in an electrolyte of $0.1 \mathrm{M} \mathrm{Ni}\left(\mathrm{NO}_{3}\right)_{2} \cdot 6 \mathrm{H}_{2} \mathrm{O}$ and $5 \mathrm{mM}$ $\mathrm{FeCl}_{2}$. The composition determine by XPS indicates a mixture of approximately $32 \% \mathrm{Fe}$ and $68 \% \mathrm{Ni}$ at the surface.

\section{Turnover frequency}

To calculate the turnover frequency (TOF) we used the following formulas:

$$
\operatorname{TOF}\left(s^{-1}\right)=\frac{r_{\mathrm{O}_{2}}}{i \text { of active sites }}
$$

The rate of $\mathrm{O}_{2}$ turnovers $\left(\mathrm{r}_{\mathrm{O} 2}\left[\mathrm{~s}^{-1}\right]\right)$ was calculated from the raw current:

$$
r_{O_{2}}=i \times\left(\frac{N_{A}}{z F}\right)
$$

Where $i(\mathrm{~A})$ is the current, $N_{A}$ is the Avogadro number $\left(6.022 \times 10^{23} \quad \mathrm{O}_{2}\right.$ molecules per mol $\left.\mathrm{O}_{2}\right), z$ the number of electrons involved in the evolution of $1 \mathrm{~mol}$ of $\mathrm{O}_{2}$ and $F(96,485$ $\mathrm{C} / \mathrm{mol}$ ) the Faraday constant.

We determined a minimum $\left(\mathrm{TOF}_{\min }\right)$ and a maximum $\left(\mathrm{TOF}_{\max }\right)$ TOF based on two different assumptions on the number of active sites.

For the calculation of $\mathrm{TOF}_{\min }$, we assumed that all metal atoms deposited are active for OER. In order to calculate the total number of $\mathrm{Ni}$ and $\mathrm{Fe}$ metal atoms deposited on the surface ( $\left.N_{\text {metal atom }}^{\text {total }}\right)$, the number of deposited particles $\left(N_{\text {particles }}\right)$ were multiplied by the average number of atoms in each particle $\left(N_{\text {metal }}^{\text {particle }}\right)$ :

$$
N_{\text {metalatom }}^{\text {total }}=N_{\text {particles }} \times N_{\text {metalatom }}^{\text {particle }}
$$


$N_{\text {particles }}$ can be calculated from the deposition current ( $I_{\text {depo }}[A]$ ), time of deposition ( $t_{\text {depo }}[s]$ ) and the electric charge $\left(6.242 \cdot 10^{-18}\right.$ electrons/C) using the following equation:

$$
N_{\text {particles }}=I_{\text {depo }} \times t_{\text {depo }} \times C
$$

Finally, to calculate the number of metal atoms in a particle, we used the deposited particle mass set by the mass filter ( $\left.m_{\text {particle }}[\mathrm{kg}]\right)$, the Avogadro constant $\left(N_{A}\left[\mathrm{~mol}^{-1}\right]\right)$ and the average molar mass ( $\left.\overline{M_{i_{x} F_{100-x}}}\left[\mathrm{~kg} \mathrm{~mol}^{-1}\right]\right)$ using the composition determined from the XPS after electrochemical treatment for each sample.

$$
N_{\text {metalatom }}^{\text {particle }}=\frac{N_{A} \times m_{\text {particle }}}{M_{i_{x}}^{\prime} E_{100-x}}
$$

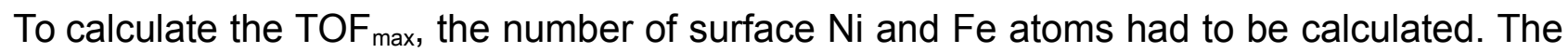
diameter of the nanoparticles was determined by TEM images, and use to calculate the surface area per particle ( $\left.A_{\text {particle }}\right)$ assuming spherical shape. This is a conservative approach since part of the nanoparticle's surface will be interfacing the substrate and therefore will not contribute to the OER. Finally, this area was multiplied by the total number of particles, $N_{\text {particles }}$, and the density of surface metal atoms to get the total number of surface $\mathrm{Ni}$ and $\mathrm{Fe}$ atoms. The assumed density of surface metal atoms ( $\rho_{\text {atoms }}$ ) of 12.5 metal atoms per $\mathrm{nm}^{2}$ is based on the metal-metal distance of $2.83 \AA$ for $\mathrm{NiFeO}_{\mathrm{x}} \mathrm{H}_{\mathrm{y}}$ measured in-situ under OER conditions ${ }^{19}$.

$$
N_{\text {surfacacatom }}^{\text {total }}=N_{\text {particles }} \times \rho_{\text {atoms }} \times A_{\text {particle }}
$$

X-ray Photoelectron Spectroscopy (XPS) and Low Energy lon Scattering (LEIS) characterization:

LEIS (Supplementary Figures 12-13) and XPS spectra (Supplementary Figures 14-16) were recorded for each sample after deposition (without breaking the vacuum) and after activity testing. In order to get rid of the remaining electrolyte on the surface after the activity test, the samples were thoroughly rinsed with ultrapure water $(18.2 \mathrm{M} \Omega \cdot \mathrm{cm})$ before loading into the UHV chamber in order to prevent the formation of a potassium layer hindering the detection of other elements.

For LEIS measurements $1 \mathrm{keV} \mathrm{He}^{+}$ions from an Omicron ISE100 ion gun were used and the energy of the scattered ions was recorded with the same 7-channel analyser used for XPS measurement operated in constant retard ratio mode (with a retard ratio of 5). The LEIS spectra presented are normalised based on the intensity of the gold peak at approx. $925 \mathrm{eV}$. 
For the XPS measurements unmonochromatized MgKa radiation from a SPECS XR50 dual filament $X$-ray gun was used. The electron energies were measured with an Omicron NanoSAM 7-channel energy analyser operated in constant pass energy mode. A pass energy of $50 \mathrm{eV}$ was chosen to increase the signal from the low loadings of nanoparticles. For each sample, a survey scan and detailed scans of $A u 4 f, O 1 s, N i p_{3 / 2}$ and $F e 2 p_{3 / 2}$ were recorded. All the spectra were charge corrected based on the $A u 4 f_{7 / 2}$ peak, which we assumed to correspond to metallic Au at $84 \mathrm{eV}$ binding energy. A Shirley background was subtracted from the detailed spectra presented and the intensities were normalised with the $\mathrm{Au} 4 \mathrm{f}$ peak area.

Identical location Scanning Electron Microscopy (SEM) imaging:

Identical location SEM imaging was performed on a sample containing $5.4 \mathrm{~nm} \mathrm{NiFe}$ particles on the Au electrode after deposition and transfer under atmospheric conditions and after electrochemical testing. SEM images were acquired at $5 \mathrm{kV}$ using an FEI Helios EBS3 microscope equipped with a field emission gun and a through-the-lens detector for high resolution imaging.

Identical location Transmission Electron Microscopy (TEM) imaging and Energy Dispersive Spectroscopy (EDX) line scans:

Identical location HRTEM images were recorded at $80 \mathrm{kV}$ electron energy, using a FEI Titan E-Cell 80-300 ST TEM with a monochromated electron source and post objective aberration correction. For the identical location TEM studies particles were deposited on $\mathrm{Au}$ coated $\mathrm{Cu}$ TEM grids with suspended monolayer graphene layers (Quantifoil, Germany). After imaging, the grids were mounted to an RDE setup and subjected to $2 \mathrm{CVs}$ at $10 \mathrm{mVs}^{-1}$ between 1 and $1.5 \mathrm{~V}_{\mathrm{RHE}}$ in $1 \mathrm{M} \mathrm{KOH}$. After the electrochemical oxidation, the particles were transferred back to the TEM and imaged a second time. EDX line scans were recorded using a silicon drift detector from Oxford Instruments on random particles before and after electrochemical oxidation.

Electrochemical Mass Spectrometry (EC-MS) experiments:

In order to investigate oxygen exchange between the NiFe particles and the electrolyte, isotopically labelled electrolyte (with ${ }^{18} \mathrm{O}$ ) and electrochemical mass spectrometry were used. The EC-MS setup is based on a micro-fabricated membrane coated with a fluorinated polymer and a well-defined capillary. Below the membrane, a small cavity is pressurized with He carrier gas and together with the capillary forces the electrolyte is kept out of the chip. The cavity is connected to a vacuum chamber equipped with a quadrupole mass spectrometer (Pfeiffer Vacuum QMA 125) through a well-defined micro-fabricated 
capillary limiting the flow of molecules to a level what can be handled by a single turbomolecular pump. For the experiments a self-designed stagnant layer electrochemical cell was used where the electrolyte thickness was $100 \mu \mathrm{m}$, which, together with the design of the vacuum chamber and microchip, gives a time response below 1s. The area under the modelled curves in Figure 8 (blue, magenta, and cyan traces) corresponds to the nominal number labelled oxygen atom in the nanoparticle samples, and the shapes of these curves were calculated by a mass transport model accounting for diffusion of $\mathrm{O}_{2}$ through the $100 \mu \mathrm{m}$ electrolyte layer. Details of the setup, experimental method, and mass transport model can be found elsewhere ${ }^{38}$. All experiments were performed using $0.1 \mathrm{M}$ $\mathrm{KOH}$ electrolyte either made with ultrapure water (natural isotope distribution) or ${ }^{18} \mathrm{O}$ enriched water $\left(97.2 \% \mathrm{H}_{2}{ }^{18} \mathrm{O}, 1.3 \% \mathrm{H}_{2}{ }^{17} \mathrm{O}, 1.5 \% \mathrm{H}_{2}{ }^{16} \mathrm{O}\right.$, Medical Isotopes). The mass spectrometer signals were calibrated internally for each experiment, as was steady-state ratio of $\mathrm{m} / \mathrm{z}=34$ to $\mathrm{m} / \mathrm{z}=36$ for procedure a. The raw data for these calibrations are shown (for procedure a) in Supplementary Figure 6.

\section{Data availability:}

The data that support the plots within this paper and other findings of this study are available from the corresponding author upon reasonable request.

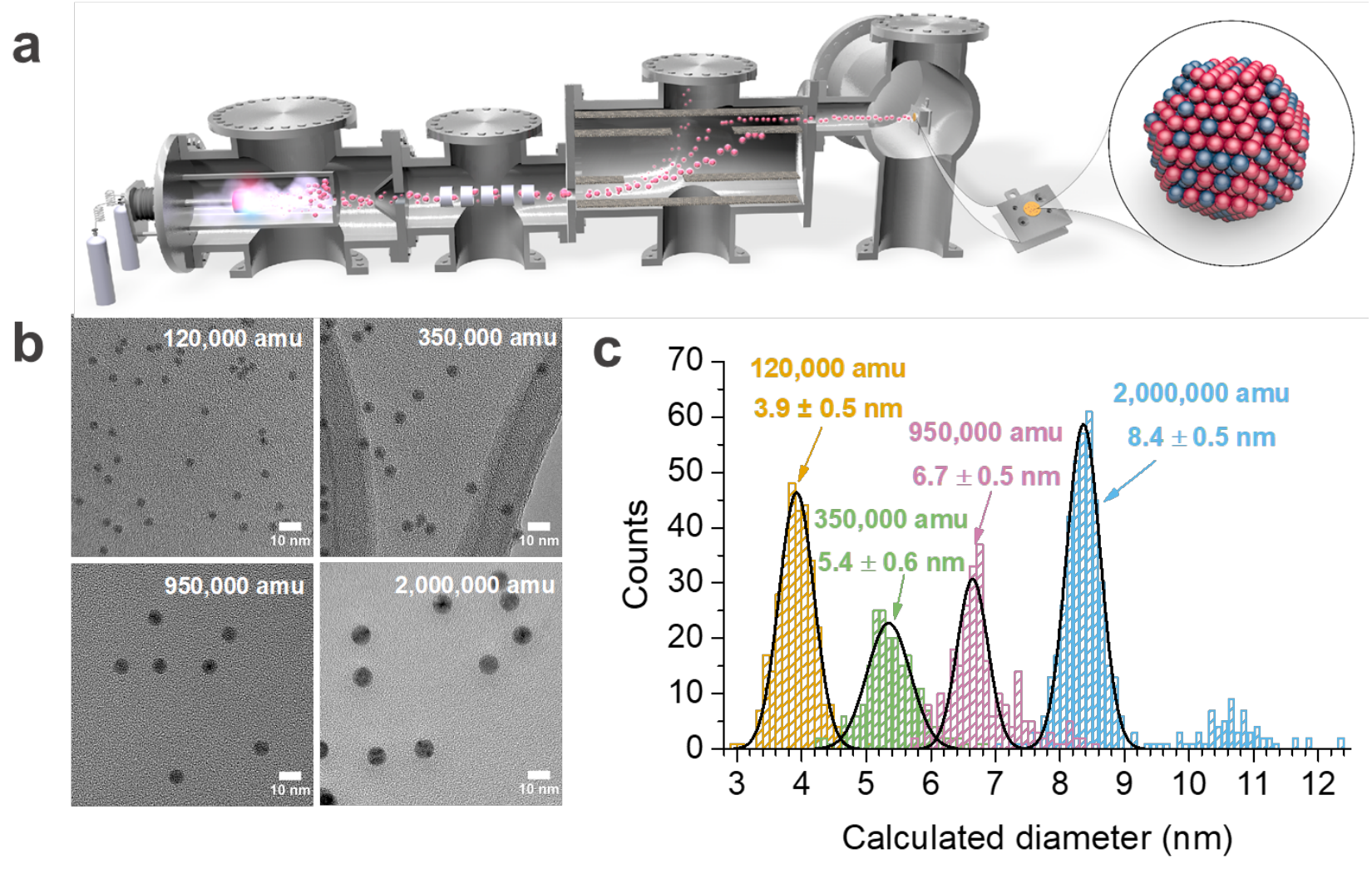


Figure 1: Deposition of mass-selected nanoparticles. (a) DC magnetron sputtering, gas aggregation mass-selected nanoparticle source with lateral time-of-flight mass filter. Mass selected NiFe nanoparticles were deposited on polycrystalline gold disks for activity measurements. (b) Transmission Electron Microscopy (TEM) images of 4 different masses of NiFe nanoparticles, and (c) size distributions determined using the diameter measured on the TEM images showing the average size and $2 \sigma$ for each mass deposited. 

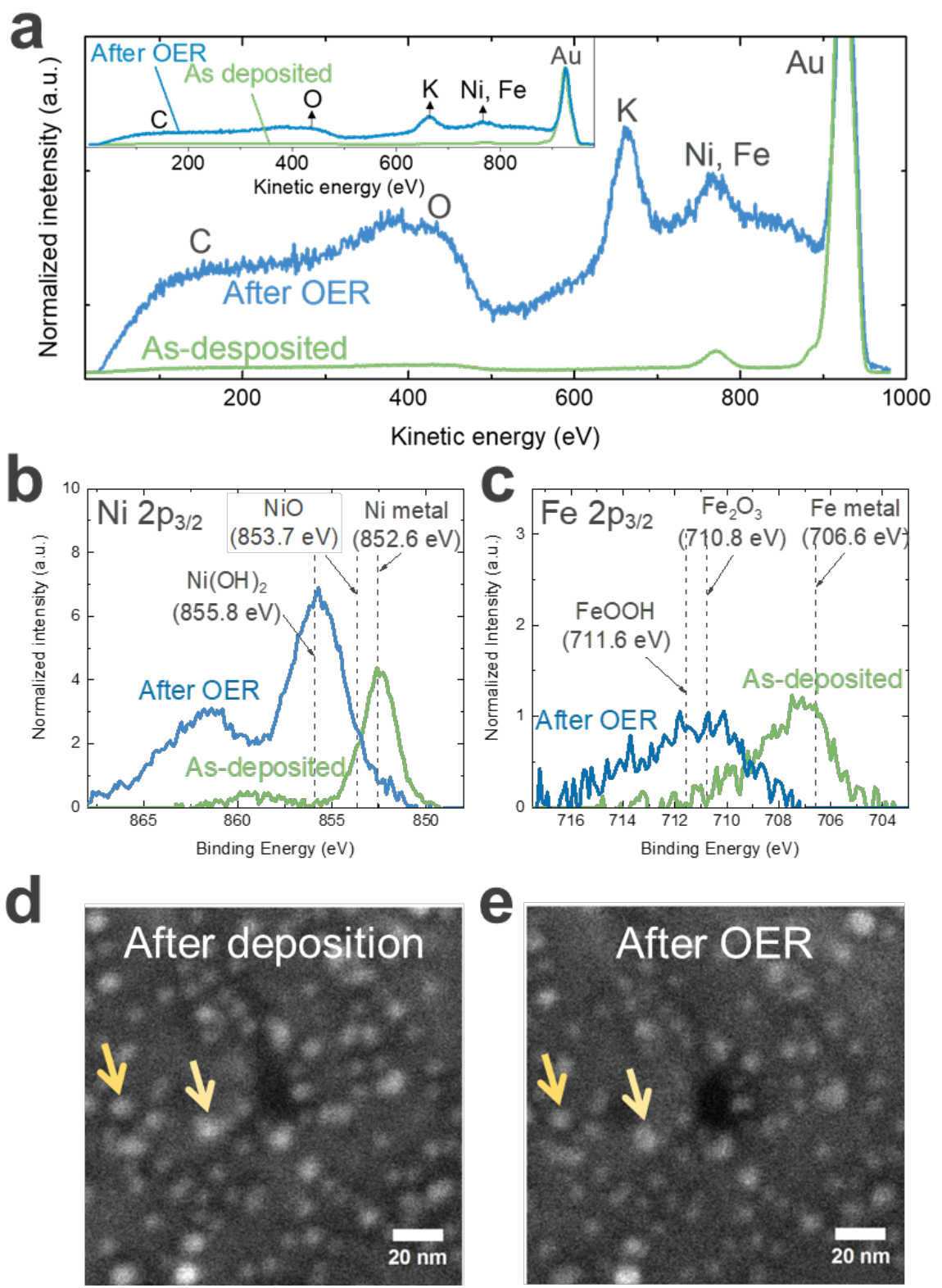

Figure 2: Ex situ characterization of the deposited $6.7 \mathrm{~nm}$ NiFe particles. (a) Low energy ion scattering (LEIS) spectra, (b-c) X-ray photoelectron spectroscopy (XPS) spectra, and scanning electron microscopy (SEM) of nanoparticles (d) as deposited and (e) after electrochemical testing. The LEIS spectra were normalized to the height of the Au peak. The XPS spectra, shown for the $\mathrm{Ni} 2 \mathrm{p}_{3 / 2}$ and $\mathrm{Fe} 2 \mathrm{p}_{3 / 2}$ regions, were charge corrected and normalized with the Au $4 \mathrm{f}$ peak area after the subtraction of a Shirley-background. The 
reference XPS binding energies were taken from References ${ }^{59-61}$. The SEM images are taken at identical location to evaluate the resistance against sintering and corrosion. 


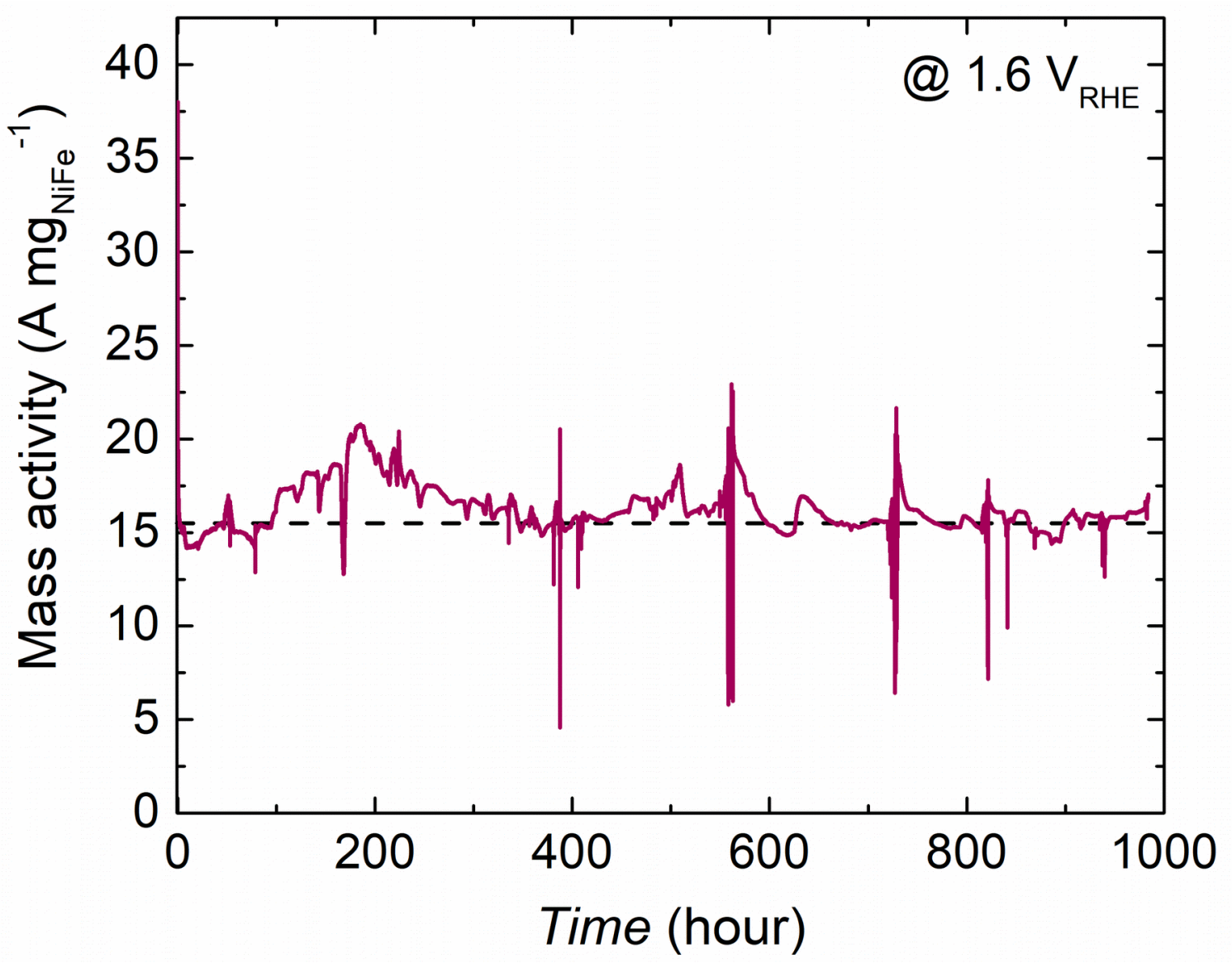

Figure 3: Stability of NiFe nanoparticles at $1.6 \mathrm{~V}_{\mathrm{RHE}}$ in $1 \mathrm{M} \mathrm{KOH}$. The figure shows the mass activity of $\sim 100 \mathrm{ng} 6.7 \mathrm{~nm}$ NiFe nanoparticles at $1.6 \mathrm{~V}_{\mathrm{RHE}}$, iR corr., in $1 \mathrm{M} \mathrm{KOH}$. The dashed line is a guide to the eye. 

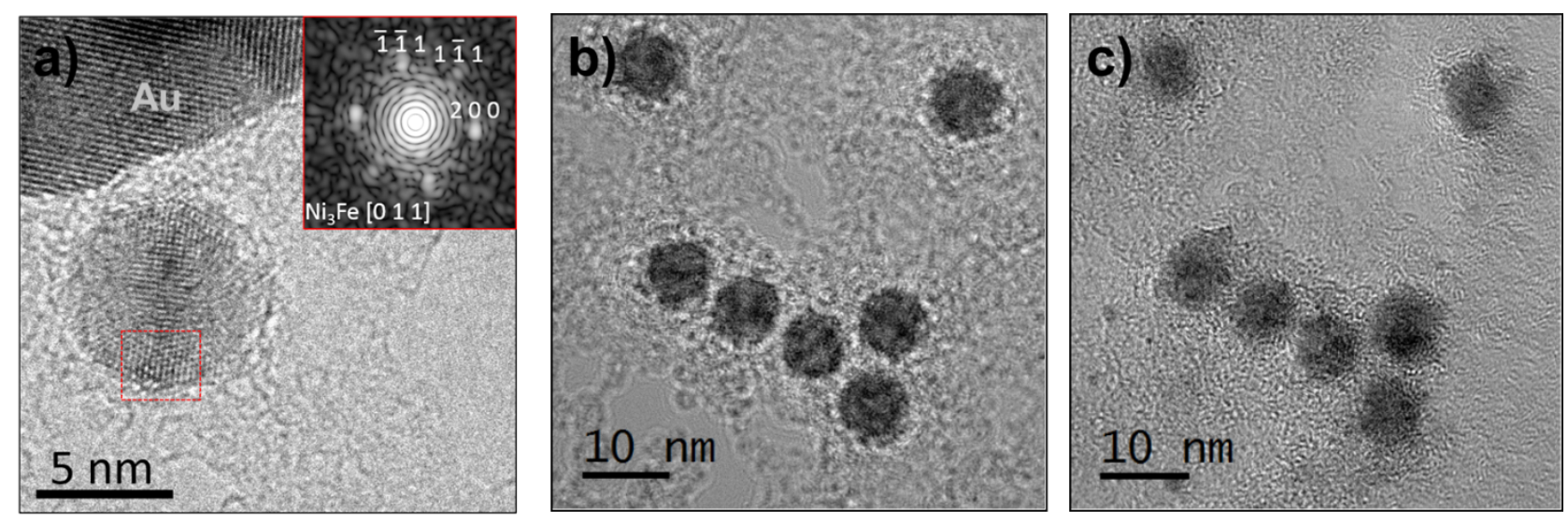

Figure 4: High-resolution TEM (HRTEM) investigation of the particles. High resolution TEM images of $6.7 \mathrm{~nm}$ (950k amu) NiFe nanoparticles deposited on Au TEM grids. (a) HRTEM image of a nanoparticle with Fourier transform of the highlighted area showing $\mathrm{Ni}_{3} \mathrm{Fe}$ phase. (b) and (c) show identical location HRTEM images of nanoparticles before (b) and after electrochemical oxidation (c). 


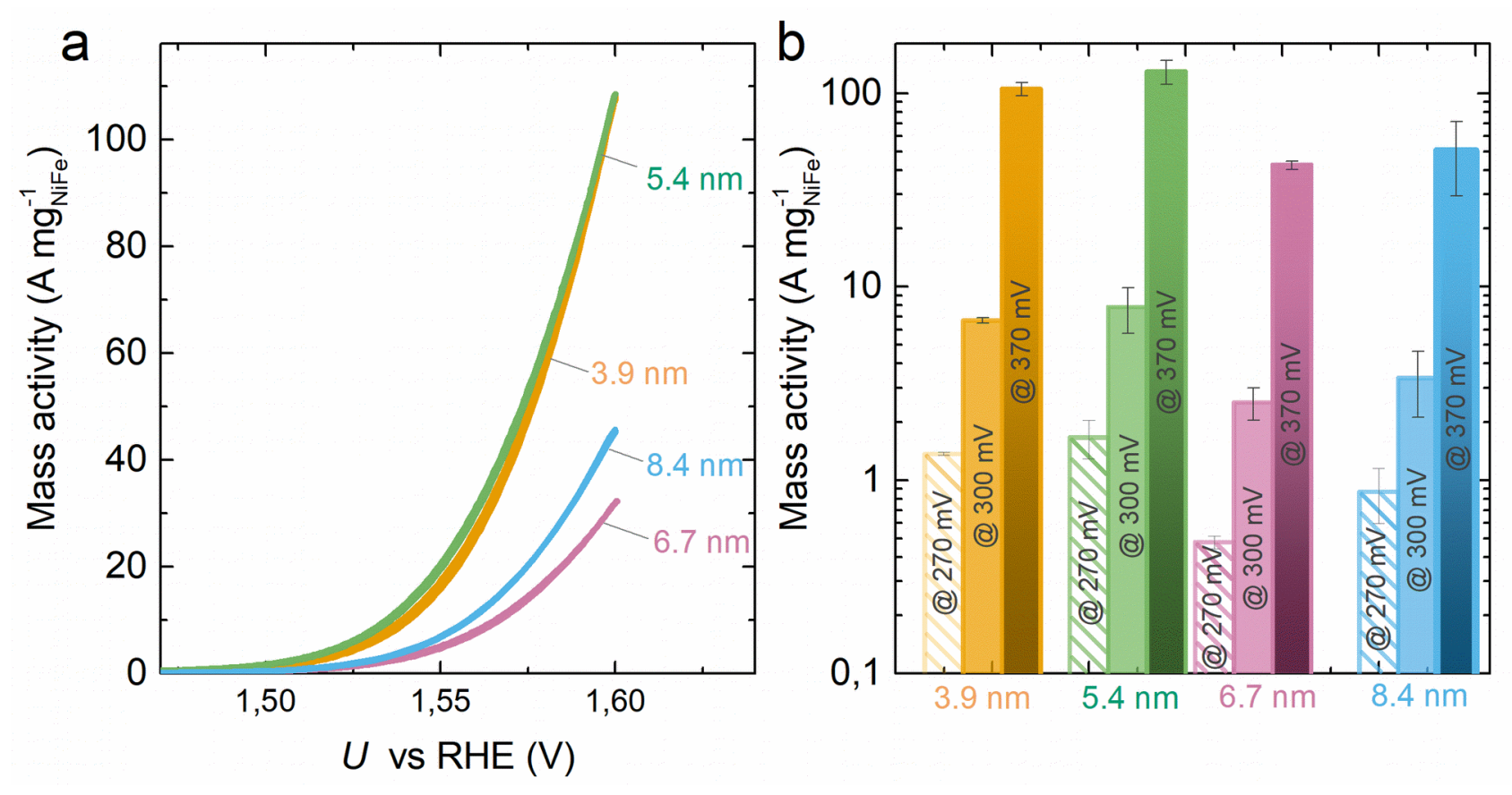

Figure 5: Catalytic activity of the NiFe nanoparticles. (a) Cyclic voltammetry at $10 \mathrm{mV} / \mathrm{s}$ of representative $\mathrm{NiFeO}_{x} \mathrm{H}_{y}$ nanoparticle samples for each nanoparticle size. The current is normalized to the total metal mass loading. (b) Mass-normalized activities at $\eta=270$, 300 and $370 \mathrm{mV}$. The average mass activity and standard deviation come from three independent samples. All activity measurements were done on $\mathrm{Au}$ substrates in $\mathrm{N}_{2}$ saturated $1 \mathrm{M} \mathrm{KOH}$ at $1,600 \mathrm{rpm}$. The metal mass was determined from the nanoparticle deposition current. 

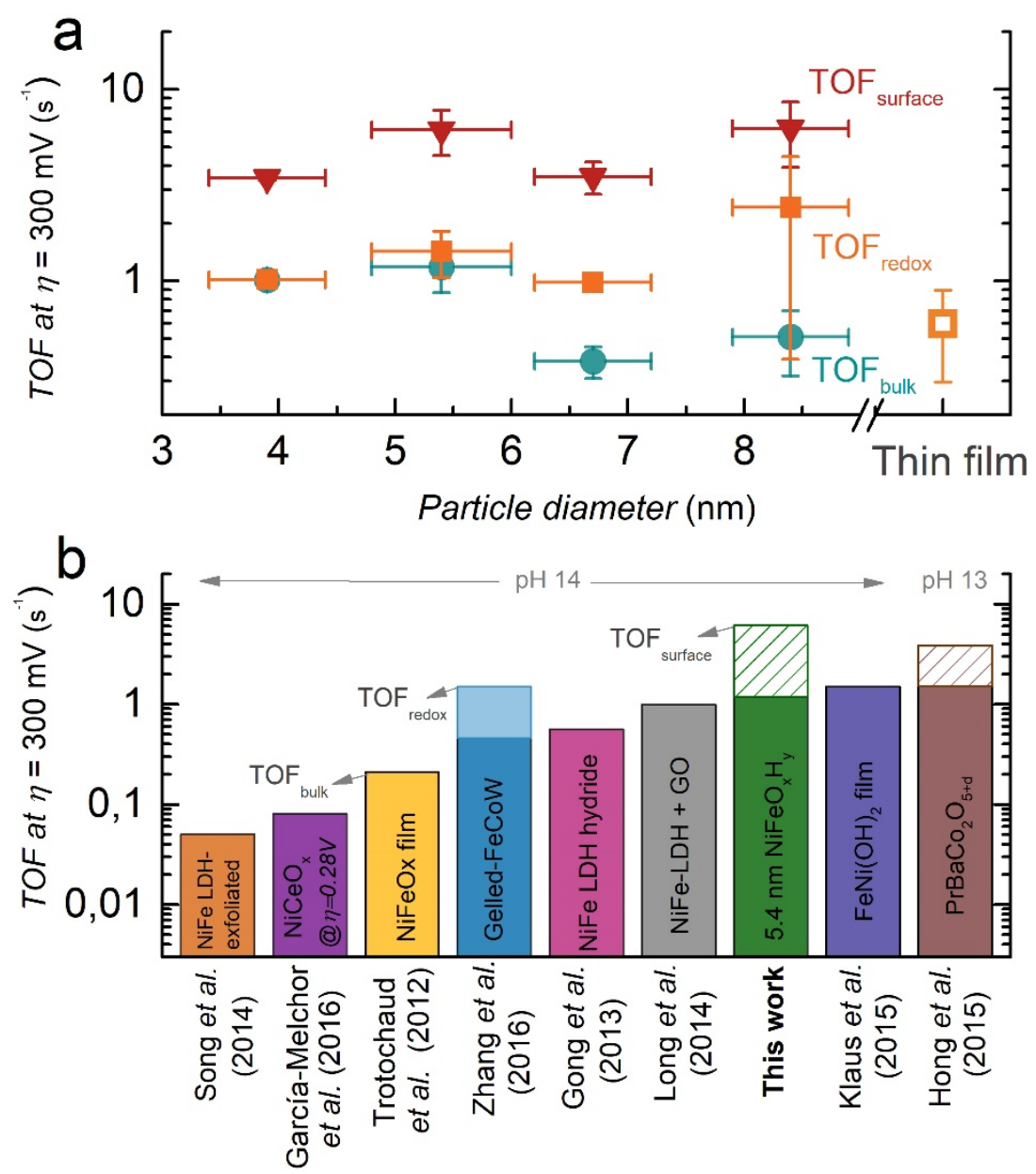

Figure 6: Turnover frequency as a function of size, and comparison to state-of-the-art nonnoble metal catalysts. (a) Turnover frequency calculated from the total metal mass (TOF buk), the $\mathrm{Ni}$ redox peak $\left(\mathrm{TOF}_{\text {redox }}\right)$, and the estimated surface atoms $\left(\mathrm{TOF}_{\text {surface }}\right)$, of the NiFe nanoparticles at $\eta=300 \mathrm{mV}$ measured in $\mathrm{N}_{2}$-saturated $1.0 \mathrm{M} \mathrm{KOH}$ at $10 \mathrm{mV} / \mathrm{s}$ as function of particle size. The $\mathrm{Ni}$ redox peak was used to measure the TOF of the NiFe thin film. The error bars come from three independent samples and where calculated using $\sqrt{\frac{\sum(x-x)^{2}}{(n-1)}}$, where $\mathrm{x}$ is the activity value and $x$ the average activity from the 3 samples (n). (b) TOF of state-of-the-art non-noble OER catalysts in alkaline. From ref. ${ }^{53}$ for NiFe LDH-Exfoliated; from ${ }^{47}$ for $\mathrm{NiCeO}_{x}$; from ${ }^{27}$ for $\mathrm{NiFeOx}$ film; from ${ }^{51}$ for Gelled-FeCoW; from ${ }^{52}$ for NiFe LDH hydride; from ${ }^{54}$ for NiFe-LDH + GO; from ${ }^{16}$ for $\mathrm{FeNi}(\mathrm{OH})^{2}$ film and from ${ }^{4}$ for $\mathrm{PrBaCO}_{2} \mathrm{O}_{5+\mathrm{d}}$. When possible both minimum (bulk, solid color) and maximum (surface, striped color, or redox, lighter shade solid color) TOF were estimated. The $\mathrm{TOF}_{\text {redox }}$ of Gelled-FeCoW was calculated using the Co redox peak, and the $\mathrm{TOF}_{\text {surf }}$ for $\mathrm{PrBaCo}_{2} \mathrm{O}_{5+d}$ was calculated based on surface area from $\mathrm{N}_{2}$ physisorption (BET). 


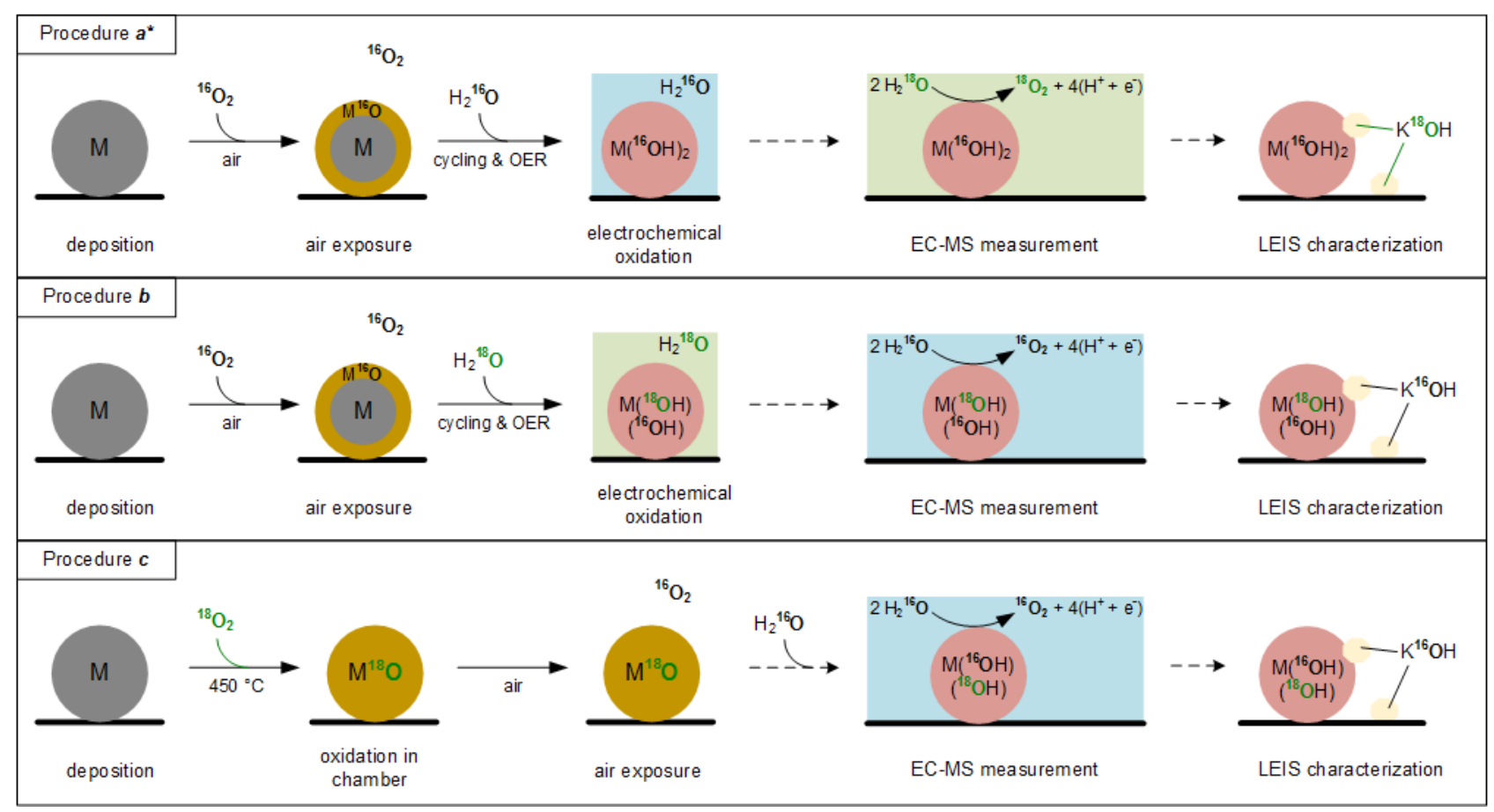

Figure 7: Isotope labelling experimental procedures. Schematic representation of the isotopic labeling experiments. Procedure a uses $\mathrm{H}_{2}{ }^{16} \mathrm{O}$ to oxidized the nanoparticles and $\mathrm{H}_{2}{ }^{18} \mathrm{O}$ for the oxygen evolution, while the opposite is done for Procedure $b$. Procedure $c$ uses ${ }^{18} \mathrm{O}_{2}$ gas to oxidize $\mathrm{NiFe}$ and the oxygen evolution is performed in ${ }^{16} \mathrm{O}$ water. In the representation, $\mathrm{M}$ refers to $\mathrm{Ni}$ and $\mathrm{Fe}$ metal atoms. ${ }^{*}$ The main text focuses on procedure a. 

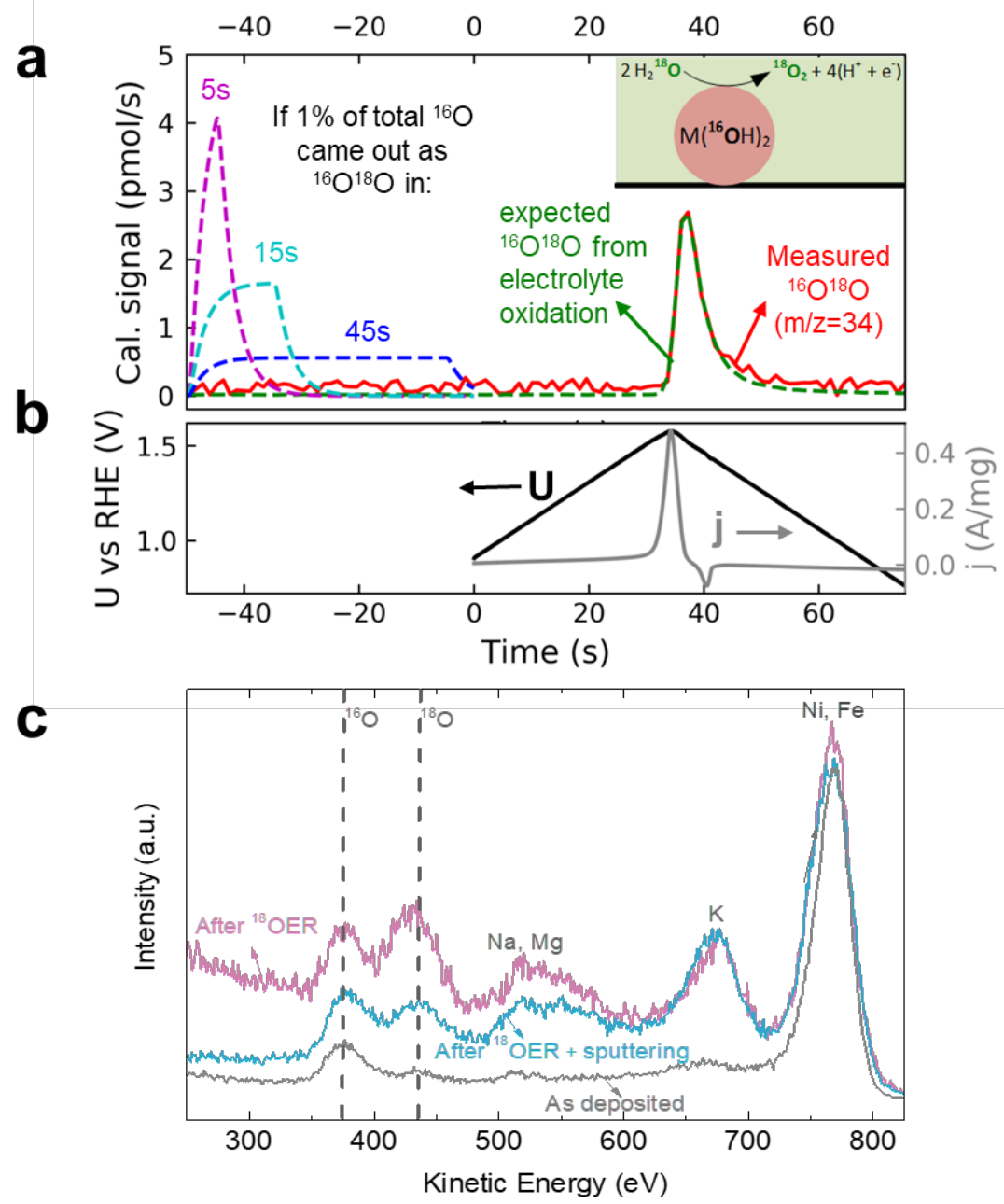
Figure 8: EC-MS and LEIS results from isotope labelling experiment using procedure a. a) First electrochemical potential cycle in $\mathrm{H}_{2}{ }^{18} \mathrm{O}$ electrolyte after sample preparation with ${ }^{16} \mathrm{O}$. calibrated mass spectrometer signal of ${ }^{16} \mathrm{O}^{18} \mathrm{O}(\mathrm{m} / \mathrm{z}=34)$ (red) detected during oxygen evolution in $0.1 \mathrm{M} \mathrm{KOH}$ made with $\mathrm{H}_{2}{ }^{18}$ Oduring the first electrochemical potential cycle after sample preparation with ${ }^{16} \mathrm{O}$. The ${ }^{16} \mathrm{O}^{18} \mathrm{O}$ signal expected without lattice exchange due to the composition of the electrolyte, which is a constant fraction of the ${ }^{18} \mathrm{O}_{2}(\mathrm{~m} / \mathrm{z}=36)$ signal, is co-plotted (dashed green). Also included are simulations of the $\mathrm{m} / \mathrm{z}=34$ signal if $1 \%$ of the total ${ }^{16} \mathrm{O}$ contained by the oxidized catalyst came out as ${ }^{18} \mathrm{O}^{16} \mathrm{O}$ in $5 \mathrm{~s}$ (magenta), $15 \mathrm{~s}$ (cyan) or $45 \mathrm{~s}$ (blue). b) The potential (black, left axis) and current (grey, right axis) from the same experiment. c) The low-energy ion scattering spectra of the sample as deposited (grey), after EC-MS experiment (purple) and after sputtering (blue). 


\section{ACKNOWLEDGEMENTS}

This work was supported by a research grant (9455) from VILLUM FONDEN. We also acknowledge UPCAT under the project no. 2015-1-12315.

\section{AUTHOR CONTRIBUTIONS}

I.E.L.S., J.K. and I.C. conceived the experiments. C.R. participated in the conception of the experiments, performed the electrochemical measurements. B.S. participated in the conception of the experiments, prepared the nanoparticles, performed the UHV experiments, S.B.S. performed and helped in the design of the EC-MS experiments. D.B.T., P.C.V. and O.H. designed and helped with the interpretation of the EC-MS experiments. E.M.F. and C.D.D. performed the microscopy characterization. J.E.S and A.B. contributed to the LEIS measurements. C.R., B.S., and S.B.S. co-wrote the manuscript. All authors discussed the results and commented on the manuscript.

\section{COMPETING INTERESTS}

The authors declare no competing interests. 


\section{REFERENCES}

1. Lewis, N. S. \& Nocera, D. G. Powering the planet: Chemical challenges in solar energy utilization. Proc. Natl. Acad. Sci. 103, 15729-15735 (2006).

2. Debe, M. K. Electrocatalyst approaches and challenges for automotive fuel cells. Nature 486, 43-51 (2012).

3. Montoya, J. H. et al. Materials for Solar Fuels and Chemicals. Nat. Mater. 16, 70-81 (2017).

4. Hong, W. T. et al. Toward the rational design of non-precious transition metal oxides for oxygen electrocatalysis. Energy Environ. Sci. 8, 1404-1427 (2015).

5. Durst, J. et al. New Insights into the Electrochemical Hydrogen Oxidation and Evolution Reaction Mechanism. Energy Environ. Sci. 7, 2255-2260 (2014).

6. Stamenkovic, V. R., Strmcnik, D., Lopes, P. P. \& Markovic, N. M. Energy and Fuels from Electrochemical Interfaces. Nat. Mater. 16, 57-69 (2017).

7. Greeley, J. \& Markovic, N. M. The road from animal electricity to green energy: combining experiment and theory in electrocatalysis. Energy Environ. Sci. 5, 9246 (2012).

8. Cifrain, M. \& Kordesch, K. Hydrogen/oxygen (air) fuel cells with alkaline electrolytes. in Handbook of Fuel Cells 1, 267-280 (John Wiley \& Sons, Ltd, 2010).

9. Pagliaro, M., Konstandopoulos, A. G., Ciriminna, R. \& Palmisano, G. Solar hydrogen: fuel of the near future. Energy Environ. Sci. 3, 279 (2010).

10. Seh, Z. W. et al. Combining Theory and Experiment in Electrocatalysis: Insights into Materials Design. Science (80-. ). 355, eaad4998 (2017).

11. The production of hydrogen and oxygen through the electrolysis of water. Scientific American Supplement No. 819 XXXII, (1891).

12. Trotochaud, L., Young, S. L., Ranney, J. K. \& Boettcher, S. W. Nickel-Iron Oxyhydroxide Oxygen-Evolution Electrocatalysts: The Role of Intentional and Incidental Iron Incorporation. J. Am. Chem. Soc. 136, 6744-6753 (2014).

13. Dionigi, F. \& Strasser, P. NiFe-Based (Oxy)hydroxide Catalysts for Oxygen Evolution Reaction in Non-Acidic Electrolytes. Adv. Energy Mater. 6, 1600621 (2016).

14. Burke, M. S., Enman, L. J., Batchellor, A. S., Zou, S. \& Boettcher, S. W. Oxygen Evolution Reaction Electrocatalysis on Transition Metal Oxides and (Oxy)hydroxides: Activity Trends and Design Principles. Chem. Mater. 27, 7549-7558 (2015).

15. Enman, L. J., Burke, M. S., Batchellor, A. S. \& Boettcher, S. W. Effects of Intentionally Incorporated Metal Cations on the Oxygen Evolution Electrocatalytic Activity of Nickel (Oxy)hydroxide in Alkaline Media. ACS Catal. 6, 2416-2423 (2016).

16. Klaus, S., Cai, Y., Louie, M. W., Trotochaud, L. \& Bell, A. T. Effects of Fe Electrolyte Impurities on $\mathrm{Ni}(\mathrm{OH})_{2} / \mathrm{NiOOH}$ Structure and Oxygen Evolution Activity. J. Phys. Chem. C 119, 7243-7254 (2015).

17. Li, N. et al. Influence of iron doping on tetravalent nickel content in catalytic oxygen evolving films. Proc. Natl. Acad. Sci. 114, 1486-1491 (2017).

18. Görlin, M. et al. Oxygen Evolution Reaction Dynamics, Faradaic Charge Efficiency, and the Active Metal Redox States of Ni-Fe Oxide Water Splitting Electrocatalysts. J. Am. Chem. Soc. 138, 5603-5614 (2016).

19. Friebel, D. et al. Identification of Highly Active $\mathrm{Fe}$ Sites in (Ni,Fe)OOH for Electrocatalytic Water Splitting. J. Am. Chem. Soc. 137, 1305-1313 (2015).

20. Stevens, M. B., Trang, C. D. M., Enman, L. J., Deng, J. \& Boettcher, S. W. Reactive Fe-Sites in Ni/Fe (Oxy)hydroxide Are Responsible for Exceptional Oxygen 
Electrocatalysis Activity. J. Am. Chem. Soc. 139, 11361-11364 (2017).

21. Hunter, B., Winkler, J. \& Gray, H. Iron Is the Active Site in Nickel/Iron Water Oxidation Electrocatalysts. Molecules 23, 903 (2018).

22. Ahn, H. S. \& Bard, A. J. Surface Interrogation Scanning Electrochemical Microscopy of $\mathrm{Ni}_{1-x} \mathrm{Fe}_{\mathrm{x}} \mathrm{OOH}(0<\mathrm{x}<0.27)$ Oxygen Evolving Catalyst: Kinetics of the "fast" Iron Sites. J. Am. Chem. Soc. 138, 313-318 (2016).

23. Xiao, H., Shin, H. \& Goddard, W. A. Synergy between Fe and Ni in the optimal performance of (Ni,Fe)OOH catalysts for the oxygen evolution reaction. Proc. Natl. Acad. Sci. 115, 5872-5877 (2018).

24. Batchellor, A. S. \& Boettcher, S. W. Pulse-Electrodeposited Ni-Fe (Oxy)hydroxide Oxygen Evolution Electrocatalysts with High Geometric and Intrinsic Activities at Large Mass Loadings. ACS Catal. 5, 6680-6689 (2015).

25. Doyle, A. D., Bajdich, M. \& Vojvodic, A. Theoretical Insights to Bulk Activity Towards Oxygen Evolution in Oxyhydroxides. Catal. Letters 147, 1533-1539 (2017).

26. Morales-Guio, C. G., Liardet, L. \& Hu, X. Oxidatively Electrodeposited Thin-Film Transition Metal (Oxy)hydroxides as Oxygen Evolution Catalysts. J. Am. Chem. Soc. 138, 8946-8957 (2016).

27. Trotochaud, L., Ranney, J. K., Williams, K. N. \& Boettcher, S. W. Solution-Cast Metal Oxide Thin Film Electrocatalysts for Oxygen Evolution. J. Am. Chem. Soc. 134, 17253-17261 (2012).

28. Wohlfahrt-Mehrens, M. \& Heitbaum, J. Oxygen evolution on Ru and $\mathrm{RuO}_{2}$ electrodes studied using isotope labelling and on-line mass spectrometry. J. Electroanal. Chem. Interfacial Electrochem. 237, 251-260 (1987).

29. Diaz-Morales, O., Calle-Vallejo, F., de Munck, C. \& Koper, M. T. M. Electrochemical water splitting by gold: evidence for an oxide decomposition mechanism. Chem. Sci. 4, 2334 (2013).

30. Fierro, S., Nagel, T., Baltruschat, H. \& Comninellis, C. Investigation of the oxygen evolution reaction on $\mathrm{Ti} / \mathrm{IrO}_{2}$ electrodes using isotope labelling and on-line mass spectrometry. Electrochem. commun. 9, 1969-1974 (2007).

31. Amin, H. M. A. \& Baltruschat, H. How many surface atoms in $\mathrm{Co}_{3} \mathrm{O}_{4}$ take part in oxygen evolution? Isotope labeling together with differential electrochemical mass spectrometry. Phys. Chem. Chem. Phys. 19, 25527-25536 (2017).

32. Surendranath, Y., Kanan, M. W. \& Nocera, D. G. Mechanistic Studies of the Oxygen Evolution Reaction by a Cobalt-Phosphate Catalyst at Neutral pH. J. Am. Chem. Soc. 132, 16501-16509 (2010).

33. Macounova, K., Makarova, M. \& Krtil, P. Oxygen evolution on nanocrystalline $\mathrm{RuO}_{2}$ and $\mathrm{Ru}_{0.9} \mathrm{Ni}_{0.1} \mathrm{O}_{2-\delta}$ electrodes - DEMS approach to reaction mechanism determination. Electrochem. commun. 11, 1865-1868 (2009).

34. Grimaud, A. et al. Activating lattice oxygen redox reactions in metal oxides to catalyse oxygen evolution. Nat. Chem. 9, 457-465 (2017).

35. Willsau, J., Wolter, O. \& Heitbaum, J. In the oxygen evolution reaction on platinum? J. Electroanal. Chem. 195, 299-306 (1985).

36. Stoerzinger, K. A. et al. Orientation-Dependent Oxygen Evolution on $\mathrm{RuO}_{2}$ without Lattice Exchange. ACS Energy Lett. 2, 876-881 (2017).

37. Lu, X. \& Zhao, C. Electrodeposition of hierarchically structured three-dimensional nickel-iron electrodes for efficient oxygen evolution at high current densities. Nat. Commun. 6, 6616 (2015).

38. Trimarco, D. B. et al. Enabling real-time detection of electrochemical desorption 
phenomena with sub-monolayer sensitivity. Electrochim. Acta 268, 520-530 (2018).

39. Paoli, E. A. et al. Oxygen Evolution on Well-Characterized Mass-Selected Ru and $\mathrm{RuO}_{2}$ Nanoparticles. Chem. Sci. 6, 190-196 (2015).

40. Li, Z. Y. et al. Three-dimensional atomic-scale structure of size-selected gold nanoclusters. Nature 451, 46-48 (2008).

41. Ferreira, P. J. et al. Instability of PtC Electrocatalysts in Proton Exchange Membrane Fuel Cells. J. Electrochem. Soc. 152, A2256 (2005).

42. Meier, J. C. et al. Design criteria for stable Pt/C fuel cell catalysts. Beilstein J. Nanotechnol. 5, 44-67 (2014).

43. Fiordaliso, E. M., Dahl, S. \& Chorkendorff, I. Strong Metal Support Interaction of Pt and Ru Nanoparticles Deposited on HOPG Probed by the H-D Exchange Reaction. J. Phys. Chem. C 116, 5773-5780 (2012).

44. Binninger, T. et al. Thermodynamic Explanation of the Universal Correlation between Oxygen Evolution Activity and Corrosion of Oxide Catalysts. Sci. Rep. 5, 12167 (2015).

45. Spöri, C., Kwan, J. T. H., Bonakdarpour, A., Wilkinson, D. P. \& Strasser, P. The Stability Challenges of Oxygen Evolving Catalysts: Towards a Common Fundamental Understanding and Mitigation of Catalyst Degradation. Angew. Chemie Int. Ed. 56, 5994-6021 (2017).

46. Hartl, K., Hanzlik, M. \& Arenz, M. IL-TEM investigations on the degradation mechanism of Pt/C electrocatalysts with different carbon supports. Energy Environ. Sci. 4, 234-238 (2011).

47. Ng, J. W. D. et al. Gold-supported cerium-doped NiOx catalysts for water oxidation. Nat. Energy 1, 16053 (2016).

48. Xu, X., Song, F. \& Hu, X. A nickel iron diselenide-derived efficient oxygen-evolution catalyst. Nat. Commun. 7, 12324 (2016).

49. Silva, $\mathrm{H}$. et al. Synthesis and characterization of $\mathrm{Fe}-\mathrm{Ni} / \mathrm{X}-\mathrm{Al}_{2} \mathrm{O}_{3}$ egg-shell catalyst for $\mathrm{H}_{2}$ generation by ammonia decomposition. Appl. Catal. A Gen. 505, 548-556 (2015).

50. Burke, M. S. et al. Revised Oxygen Evolution Reaction Activity Trends for First-Row Transition-Metal (Oxy)hydroxides in Alkaline Media. J. Phys. Chem. Lett. 6, 37373742 (2015).

51. Zhang, B. et al. Homogeneously dispersed multimetal oxygen-evolving catalysts. Science. 352, 333-337 (2016).

52. Gong, M. et al. An Advanced Ni-Fe Layered Double Hydroxide Electrocatalyst for Water Oxidation. J. Am. Chem. Soc. 135, 8452-8455 (2013).

53. Song, F. \& Hu, X. Exfoliation of layered double hydroxides for enhanced oxygen evolution catalysis. Nat. Commun. 5, 4477 (2014).

54. Long, X. et al. A Strongly Coupled Graphene and FeNi Double Hydroxide Hybrid as an Excellent Electrocatalyst for the Oxygen Evolution Reaction. Angew. Chemie Int. Ed. 53, 7584-7588 (2014).

55. Wehrens-Dijksma, M. \& Notten, P. H. L. Electrochemical Quartz Microbalance characterization of $\mathrm{Ni}(\mathrm{OH})_{2}$-based thin film electrodes. Electrochim. Acta 51, 36093621 (2006).

56. Lu, X. \& Zhao, C. Electrodeposition of hierarchically structured densities. Nat. Commun. 6, 1-7 (2015).

57. von Issendorff, B. \& Palmer, R. E. A new high transmission infinite range mass selector for cluster and nanoparticle beams. Rev. Sci. Instrum. 70, 4497-4501 (1999). 
58. Pratontep, S., Carroll, S. J., Xirouchaki, C., Streun, M. \& Palmer, R. E. Size-selected cluster beam source based on radio frequency magnetron plasma sputtering and gas condensation. Rev. Sci. Instrum. 76, 045103 (2005).

59. Biesinger, M. C., Lau, L. W. M., Gerson, A. R. \& Smart, R. S. C. The role of the Auger parameter in XPS studies of nickel metal, halides and oxides. Phys. Chem. Chem. Phys. 14, 2434 (2012).

60. Biesinger, M. C. et al. Resolving surface chemical states in XPS analysis of first row transition metals, oxides and hydroxides: Cr, Mn, Fe, Co and Ni. Appl. Surf. Sci. 257, 2717-2730 (2011).

61. Grosvenor, A. P., Biesinger, M. C., Smart, R. S. C. \& Mclntyre, N. S. New interpretations of XPS spectra of nickel metal and oxides. Surf. Sci. 600, 1771-1779 (2006). 